\title{
Evaluation of Predictors for Safe Motherhood Among Tribal Women in Bangladesh Chittagong Hill Tracts
}

\author{
Abu Naser Md. Rezaul Karim ${ }^{1 *}$, S.M. Mostafa Kamal ${ }^{2}$
}

\begin{abstract}
Objectives: Bangladesh is a country which is known for its flora and fauna in South Asia. Despite embracing safe motherhood and adhering to the advice of the International Community, with remarkable progress towards achieving the maternal mortality Millennium Development Goals (MDG) 5 goal, its development contrasts with the tribal people who reside in the remote hilly regions of the country. Therefore, this study was intended to identify the predictors that affect secure maternity practices among the tribal women of Chittagong Hill Tracts (CHT), Bangladesh.

Materials and Methods: This study adopted a cross-sectional approach and was performed with live births of 556 married tribal females aged 15 to 49 years from three districts of CHT when the age of their children was not more than 1 year. Semi-structured questionnaires were used to interview the subjects. Finally, the statistical analysis was conducted with SPSS20 to estimate the odds ratios and strength of the relationship between the variables at $P<0.10$.

Results: The results of the study revealed that safe maternity practices are not the standard in CHT. Only $12.7 \%$ met the standard of maternity services in CHT. At the time of pregnancy, more than $2 / 3$ of females received no prenatal care. The results further demonstrated that only $34 \%$ of the women gave birth to the baby at a hospital while $66 \%$ of the births occurred at home and over $50 \%$ were assisted by untrained traditional midwives.

Conclusions: In general, the results revealed that socioeconomic, demographic, cultural, and behavioral factors affected the adoption of maternal health care services (MHCS) by the women of CHT. Therefore, improving the economic conditions by introducing 'ecofriendly' industries can help enhance the uptake of safe motherhood practices.

Keywords: Safe motherhood, Prenatal care, Skilled birth attendant, Place of delivery, Postpartum care, Tribal women
\end{abstract}

\section{Introduction}

Pregnancy and motherhood are regarded as crucial natural evolutions in the regenerative nature of the female physiology. Although both processes are deemed to be constructive and complimentary, this is unfortunate that a good number of maternal deaths occurs throughout pregnancy, labor, and postpartum.

Enhancing and securing maternal well-being (fitness) and trimming down the rate of maternal mortality, especially during childbirth, do not merely signify health issues, instead, they cover the major critical areas of human rights. In addition, the growing concern of the present world regarding improving the health of the mothers during their productivity has resulted in a widespread claim for thinking and rethinking, particularly in the ground of maternal health. Safe motherhood is a series of practices, initiatives, and service delivery aspects that ensures adequate and quality care for mothers and children throughout gestation conditions, parturition, and the postpartum. Prenatal care is the first step on the top ladder toward achieving safe maternity care (1). For adopting safe motherhood, the World Health Organization has always emphasized the need for promotional activities regarding maternal health. In 1987, a world conference on the adoption of safe motherhood was held in the Kenyan capital, Nairobi.

The death of a good number of mothers due to childbirth-related issues has caused about 830 global deaths daily $(2,3)$. Given a prevalence of about $99 \%$ in the rural areas of developing countries, maternal mortality occurs during labor, childbirth, or early postpartum. Global maternal death has made a 44\% decrease from 385 deaths $/ 10^{5}$ to 216 deaths $/ 10^{5}$ live births between 1990 and 2015. A $7.3 \%$ annual reduction rate is required to obtain Sustainable Development Goal 3 (SDG-3) by 2030. This has led to further efforts regarding decreasing maternal death to less than 70 deaths $/ 10^{5}$ live births (3).

For instance, Bangladesh has recorded a good-sized reduction in the rate of maternal death (from 569 to 176 deaths $/ 10^{5}$ live births) between 2009 and 2015 (2). Although maternal mortality rates are decreasing day by day, the rate is higher in the village compared to the city. According to the Bangladesh Bureau of Statistics (BBS) survey, the maternal mortality rate is 1.32 and 1.93 in the 
city and the village, respectively. About 3500000 pregnant women give birth to babies every year in Bangladesh. However, there are not enough skilled human resources to serve these women in the country (4).

The south and south-eastern parts of Bangladesh are hilly regions which are inhabited by tribal people. They have been isolated geographically, culturally, economically, behaviorally, socially, and politically from the mainstream people (5). In the case of social and economic problems, indigenous peoples may be considered as the weakest group in the country (6). Further, the maternal health of Chittagong Hill Tracts (CHT) tribal women is deplorable due to poor adoption of safe motherhood practices. Hence, this study aimed to determine the predictors influencing safe maternity practices among Bangladesh tribal women of CHT.

\section{Materials and Methods}

The present study adhered to a cross-sectional method using a convenient sampling technique. Married women within the age range of 15-49 years with live birth a year before the survey were randomly selected for the study from among the three districts which made up the CHT, namely, Rangamati, Khagrachari, and Bandarban (10, 8, and 7 Upazilas, respectively). On the other hand, women above 49 years living outside the three districts of CHT and those with live birth less than twelve months prior to the survey were excluded from the study. A total sample(n) of 556 married tribal women was used and data were obtained using a semi-structured questionnaire. All data were analyzed by using the SPSS software, version 20. The associations were determined using the chi-square test, followed by performing a binary logistic regression analysis in order to isolate factors related to maternal health care services (MHCS) among the samples. Furthermore, the odds ratio (OR) was calculated using the multivariate analysis with a confidence interval (CI) of $95 \%$ to estimate the strength of the link between the indicators and the exposure with significance at a $P$ value of $<0.10$.

Sample Size Calculation

As per Cochran's rule

$n=\frac{z^{2} p q}{d^{2}}$

$n=\frac{1.96 \times 1.96 \times 0.5 \times 0.5}{0.05 \times 0.05}=384$

For an adequate representation of the study population, an additional 50\% (i.e., 192 participants) were added to the calculated sample size (i.e., 384+192) giving a total of 576 respondents for the survey. For this study, at least 22 houses were selected from each sub-district to survey and a total of 556 households was covered within the 25 sub-districts. However, 20 of these households did not participate in the study.

Theoretical Framework

In this study, four components were treated as standard safe maternity care practitioners. They included women who met the doctors at least 4 times for a prenatal check-up; those who visited the antenatal care (ANC) within three months of pregnancy; those who received an institutional delivery (gave birth to a child) with a skilled birth attendant (SBA); and those who maintained a postpartum checkup (PNC) within 48 hours of birth (Figure 1).

\section{Exposures Variables}

In this research, the exposure factors or independent variables included the following criteria.

Economic and Demographic Factors: Wealth index, parity, women's occupation, the family size, women's educational status, the spouse's occupation, media exposure, respondents' age at the first marriage, husbands' educational status, distance to the nearest health centre, the place of residence, and the like.

Cultural and Behavioral Factors: Religion, tribal identity, and family planning.

\section{Dependent Variables}

As already highlighted, the outcomevariables encompassed safe motherhood practices which are assessed using four indicators or outcome measures including ANC, practices for childbirth, trained birth attendant (SBA), and PNC.

\section{Results}

Data in Figure 2a indicates that only $14 \%$ of pregnant women went to the ANC more than 3 times whereas $70 \%$ of them received no prenatal care during pregnancy.

In addition, Figure $2 \mathrm{~b}$ describes that only $16 \%$ of women began receiving ANC care within three months

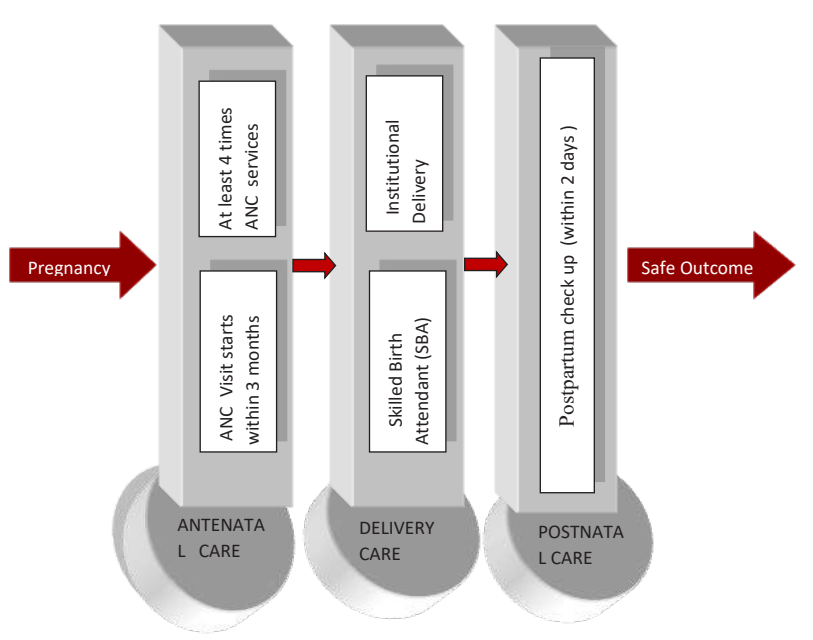

Figure 1. Practice for Standard Safe Motherhood. 


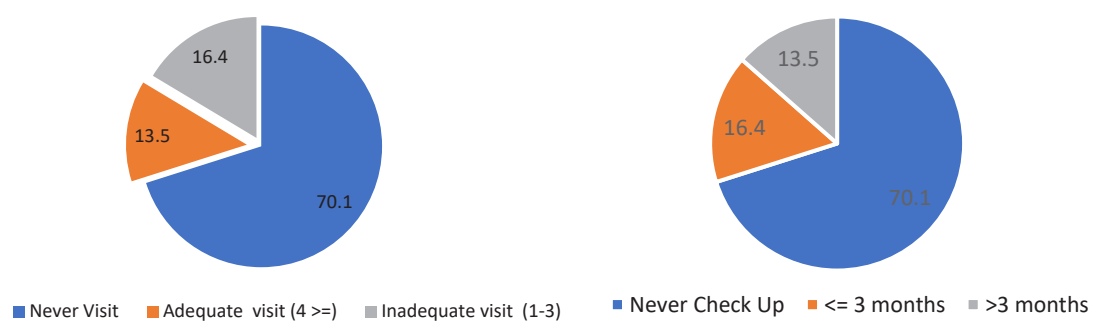

Figure 2. (a) Adequacy of ANC. (b) Delay ANC.

$(\leq 3)$ while $14 \%$ began receiving ANC care after 3 months $(\geq)$ of pregnancy.

Figure 3 is the summary of MHCS uptake among tribal women in CHT, Bangladesh. As shown, 30\% and 14\% of the women had a minimum of one and at least four visits to ANC during their pregnancy, respectively. Only $34 \%$ and $12 \%$ of females gave birth to an infant in a health facility and at home with SBAs, respectively.

Further, postnatal check-up received within 2 and 48 days postpartum by these women was $32 \%$ and $36 \%$, respectively, and the full utilization (standard safe motherhood practices) of MHCS was only $12.7 \%$.

In this study, only $12.7 \%$ of tribal women met doctors at least 4 times for a prenatal check-up and visited the ANC within 3 months of pregnancy, followed by receiving an institutional delivery (gave birth to a child) with a SBA and a postpartum check-up within two days of birth (Figure 4).

Based on the data in Table 1, increasing distances from health facilities are implicated by a decrease in women assessing prenatal care services for the period of pregnancy. However, the results indicate a strong association between women with higher education and the observance family planning as the predictors for assessing prenatal care services. The wealth index is also a strong predictor for women assessing ANC. Furthermore, the middle and affluent wealth index has a strong association with assessing ANC services. However, there is no important connection between the education of the husband and the

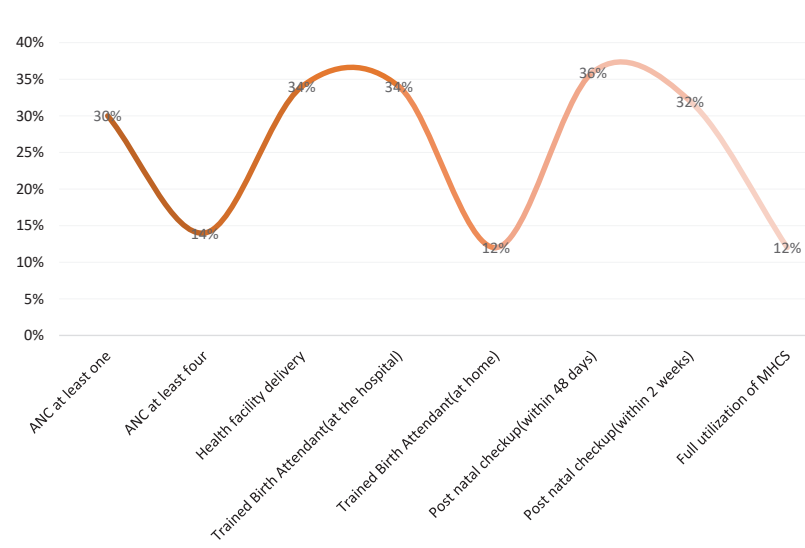

Figure 3. MHCS Utilization Among Tribal Women in $\mathrm{CHT}$, Bangladesh. adoption of the ANC.

Table 2 describes some of the main healthcare predictors of childbirth. Based on the data, age at first marriage less than 18 had no association with the use of institutional delivery. However, at married women above 18, it could be a possible indicator for the utilization of institutional delivery. The wealth index for the middle class and affluent is a reliable indicator of institutional delivery. A higher degree is a strong indicator regarding assessing the institution for birth. In the urban environment, women have an additional opportunity for using institutional delivery.

Table 3 highlights the influence of the wealth index of the middle and wealthy class as a positive predictor for women to seek SBAs during childbirth. Moreover, exposure of women to media and higher education showed a strong association with women who sought SBAs during childbirth.

Table 4 demonstrates the connection between some key predictors that influence women in their search for postnatal care services in CHT, Bangladesh.

The results indicated that the wealth index among the middle and wealthy class had a robust positive relationship with women who sought postnatal care. Husbands and women with higher education and media exposure are strong predictors for women who seek PNC. Urban settings elucidated in the result further exerted a strong influence on women seeking PNC.

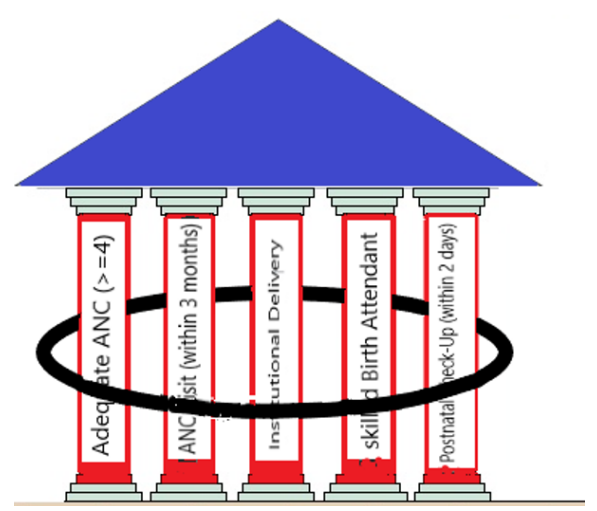

Figure 4. Standard Safe Motherhood Utilization Among Tribal Women in $\mathrm{CHT}$. Only $12.7 \%$ of tribal women of Bangladesh maintain standard safe motherhood practices. 
Table 1. Regression Analysis of Prenatal Care Services During Gestation

\begin{tabular}{|c|c|c|c|c|c|c|c|}
\hline \multirow{2}{*}{ Variables } & \multirow{2}{*}{ B } & \multirow{2}{*}{ SE } & \multirow{2}{*}{$d f$} & \multirow{2}{*}{$P$ Value } & \multirow{2}{*}{ Odds Ratio } & \multicolumn{2}{|c|}{ 95\% Cl for EXP (B) } \\
\hline & & & & & & Lower & Upper \\
\hline \multicolumn{8}{|l|}{ Wealth index } \\
\hline Poor & & & 2 & 0 & 1 & & \\
\hline Middle & 1.452 & 0.366 & 1 & 0 & $4.272^{* * *}$ & 2.086 & 8.75 \\
\hline Rich & 2.039 & 0.377 & 1 & 0 & $7.680^{* * *}$ & 3.665 & 16.092 \\
\hline \multicolumn{8}{|c|}{ Distance to a health facility } \\
\hline$<5$ & & & 2 & 0 & 1 & & \\
\hline $5-10$ & -1.307 & 0.323 & 1 & 0 & $0.271^{* * *}$ & 0.144 & 0.509 \\
\hline $10+$ & -1.623 & 0.285 & 1 & 0 & $0.197^{* * *}$ & 0.113 & 0.345 \\
\hline \multicolumn{8}{|c|}{ Husbands' education } \\
\hline Illiterate & & & 3 & 0.04 & 1 & & \\
\hline Primary & -0.629 & 0.612 & 1 & 0.304 & $0.533^{\mathrm{ns}}$ & 0.161 & 1.768 \\
\hline Secondary & -0.237 & 0.569 & 1 & 0.677 & $0.789^{\text {ns }}$ & 0.259 & 2.406 \\
\hline Higher & 0.589 & 0.612 & 1 & 0.336 & $1.803^{\mathrm{ns}}$ & 0.543 & 5.984 \\
\hline \multicolumn{8}{|c|}{ Education of women } \\
\hline Illiterate & & & 3 & 0.013 & 1 & & \\
\hline Primary & -0.178 & 0.437 & 1 & 0.683 & $0.837^{\mathrm{ns}}$ & 0.355 & 1.97 \\
\hline Secondary & 0.048 & 0.436 & 1 & 0.913 & $1.049^{\mathrm{ns}}$ & 0.446 & 2.464 \\
\hline Higher & 1.065 & 0.497 & 1 & 0.032 & $2.900^{* *}$ & 1.095 & 7.678 \\
\hline \multicolumn{8}{|c|}{ Family planning } \\
\hline No & & & & & 1 & & \\
\hline Yes & 0.708 & 0.252 & 1 & 0.005 & $2.031^{* * *}$ & 1.24 & 3.326 \\
\hline
\end{tabular}

Note. Ns: Not significant; $\mathrm{Cl}$ : confidence interval; SE: standard error.

${ }^{*} P<0.10 ;{ }^{* *} P<0.05 ;{ }^{* * *} P<0.01$.

Table 2. Regression Analysis for the Birth of a Baby in Institutional Delivery

\begin{tabular}{|c|c|c|c|c|c|c|c|}
\hline \multirow{2}{*}{ Variables } & \multirow{2}{*}{ B } & \multirow{2}{*}{ SE } & \multirow{2}{*}{$d f$} & \multirow{2}{*}{$P$ Value } & \multirow{2}{*}{ Odds Ratio } & \multicolumn{2}{|c|}{ 95\% Cl for EXP (B) } \\
\hline & & & & & & Lower & Upper \\
\hline \multicolumn{8}{|c|}{ Age at first marriage } \\
\hline$<18$ & & & & & 1 & & \\
\hline $18+$ & 0.699 & 0.318 & 1 & 0.028 & $2.012^{* *}$ & 1.079 & 3.75 \\
\hline \multicolumn{8}{|l|}{ Group of tribal } \\
\hline Chakma & & & 3 & 0.082 & 1 & & \\
\hline Marma & -0.573 & 0.299 & 1 & 0.056 & $0.564^{*}$ & 0.314 & 1.014 \\
\hline Tripura & -0.104 & 0.538 & 1 & 0.847 & $0.901^{\mathrm{ns}}$ & 0.314 & 2.589 \\
\hline Other & -1.231 & 0.617 & 1 & 0.046 & $0.292^{* *}$ & 0.087 & 0.979 \\
\hline \multicolumn{8}{|l|}{ Family planning } \\
\hline No & & & & & 1 & & \\
\hline Yes & 0.365 & 0.262 & 1 & 0.164 & $1.440^{\mathrm{ns}}$ & 0.861 & 2.408 \\
\hline \multicolumn{8}{|l|}{ Wealth index } \\
\hline Poor & & & 2 & 0 & 1 & & \\
\hline Middle & 1.19 & 0.345 & 1 & 0.001 & $3.287^{* * *}$ & 1.673 & 6.457 \\
\hline Rich & 2.057 & 0.363 & 1 & 0 & $7.821^{* * *}$ & 3.842 & 15.92 \\
\hline \multicolumn{8}{|c|}{ Husband's occupation } \\
\hline Agriculture & & & 3 & 0 & 1 & & \\
\hline Business & 1.149 & 0.318 & 1 & 0 & $3.154^{* * *}$ & 1.69 & 5.885 \\
\hline Service & 1.369 & 0.352 & 1 & 0 & $3.931^{* * *}$ & 1.973 & 7.831 \\
\hline Day laborer & -0.219 & 0.617 & 1 & 0.723 & $0.803^{\mathrm{ns}}$ & 0.24 & 2.693 \\
\hline \multicolumn{8}{|c|}{ Distance to a health facility } \\
\hline$<5$ & & & 2 & 0.009 & 1 & & \\
\hline $5-10$ & -0.581 & 0.348 & 1 & 0.095 & $0.560^{* * *}$ & 0.283 & 1.107 \\
\hline $10+$ & -0.95 & 0.309 & 1 & 0.002 & $0.387^{* * *}$ & 0.211 & 0.709 \\
\hline \multicolumn{8}{|c|}{ Women's education } \\
\hline Illiterate & & & 3 & 0.018 & 1 & & \\
\hline Primary & -0.116 & 0.399 & 1 & 0.77 & $0.890^{\mathrm{ns}}$ & 0.407 & 1.946 \\
\hline Secondary & 0.21 & 0.385 & 1 & 0.585 & $1.234^{\mathrm{ns}}$ & 0.58 & 2.624 \\
\hline Higher & 1.097 & 0.453 & 1 & 0.015 & $2.996 * *$ & 1.233 & 7.276 \\
\hline \multicolumn{8}{|l|}{ Dwelling place } \\
\hline Rural & & & & & 1 & & \\
\hline Urban & 0.773 & 0.341 & 1 & 0.023 & $2.165^{* *}$ & 1.11 & 4.224 \\
\hline
\end{tabular}

Note. Ns: Not significant; $\mathrm{Cl}$ : confidence interval; SE: standard error.

${ }^{*} P<0.10 ;{ }^{* *} P<0.05 ;{ }^{* * *} P<0.01$. 
Table 3. Binary Logistic Regression Analysis of Skilled Birth Attendant at Childbirth

\begin{tabular}{|c|c|c|c|c|c|c|c|}
\hline \multirow{2}{*}{ Variables } & \multirow{2}{*}{ B } & \multirow{2}{*}{ SE } & \multirow{2}{*}{$d f$} & \multirow{2}{*}{$P$ Value } & \multirow{2}{*}{ Odds Ratio } & \multicolumn{2}{|c|}{ 95\% Cl for EXP (B) } \\
\hline & & & & & & Lower & Upper \\
\hline \multicolumn{8}{|c|}{ Age of husband } \\
\hline$<25$ & & & 2 & 0.685 & 1 & & \\
\hline $25-35$ & 0.242 & 0.28 & 1 & 0.388 & $1.274^{\mathrm{ns}}$ & 0.736 & 2.206 \\
\hline $35+$ & 0.147 & 0.412 & 1 & 0.721 & $1.159^{\text {ns }}$ & 0.516 & 2.6 \\
\hline \multicolumn{8}{|l|}{ Parity } \\
\hline $1-2$ & & & & & 1 & & \\
\hline 3 and more & -0.222 & 0.298 & 1 & 0.456 & $0.801^{\mathrm{ns}}$ & 0.446 & 1.436 \\
\hline \multicolumn{8}{|l|}{ Wealth index } \\
\hline Poor & & & 2 & 0 & 1 & & \\
\hline Middle & 1.253 & 0.288 & 1 & 0 & $3.502^{* * *}$ & 1.99 & 6.162 \\
\hline Rich & 1.14 & 0.353 & 1 & 0.001 & $3.128^{* * *}$ & 1.567 & 6.243 \\
\hline \multicolumn{8}{|c|}{ Women's education } \\
\hline Illiterate & & & 3 & 0.01 & 1 & & \\
\hline Primary & 0.973 & 0.337 & 1 & 0.004 & $2.647^{* * *}$ & 1.368 & 5.12 \\
\hline Secondary & 0.492 & 0.348 & 1 & 0.157 & $1.636^{\mathrm{ns}}$ & 0.828 & 3.233 \\
\hline Higher & 1.19 & 0.455 & 1 & 0.009 & $3.288^{* * *}$ & 1.347 & 8.025 \\
\hline \multicolumn{8}{|c|}{ Husbands' ccupation } \\
\hline Agriculture & & & 3 & 0 & 1 & & \\
\hline Business & 1.011 & 0.323 & 1 & 0.002 & $2.747^{* * *}$ & 1.458 & 5.178 \\
\hline Service & 1.487 & 0.379 & 1 & 0 & $4.423^{* * *}$ & 2.104 & 9.298 \\
\hline Day laborer & 0.261 & 0.468 & 1 & 0.577 & $1.299^{\mathrm{ns}}$ & 0.518 & 3.253 \\
\hline \multicolumn{8}{|c|}{ Dwelling place } \\
\hline Rural & & & & & 1 & & \\
\hline Urban & 0.568 & 0.361 & 1 & 0.115 & $1.765^{\mathrm{ns}}$ & 0.871 & 3.578 \\
\hline \multicolumn{8}{|c|}{ Distance to a health facility } \\
\hline$<5$ & & & 2 & 0.003 & 1 & & \\
\hline 05-10 & -0.482 & 0.334 & 1 & 0.149 & $0.618^{\mathrm{ns}}$ & 0.321 & 1.187 \\
\hline $10+$ & -1.022 & 0.302 & 1 & 0.001 & $0.360^{* * *}$ & 0.199 & 0.65 \\
\hline \multicolumn{8}{|c|}{ Media exposure (watching TV) } \\
\hline No & & & & & 1 & & \\
\hline Yes & 0.803 & 0.298 & 1 & 0.007 & $2.232^{* * *}$ & 1.245 & 4.004 \\
\hline \multicolumn{8}{|c|}{ Group of tribal } \\
\hline Chakma & & & 3 & 0.04 & 1 & & \\
\hline Marma & -0.428 & 0.279 & 1 & 0.125 & $0.652^{\mathrm{ns}}$ & 0.377 & 1.127 \\
\hline Tripura & 1.4 & 0.809 & 1 & 0.083 & $4.057^{*}$ & 0.831 & 19.815 \\
\hline Other & -0.838 & 0.535 & 1 & 0.117 & $0.433^{\mathrm{ns}}$ & 0.152 & 1.235 \\
\hline \multicolumn{8}{|l|}{ Religion } \\
\hline Buddhist & & & & & 1 & & \\
\hline Other & -1.181 & 0.733 & 1 & 0.107 & $0.307^{\mathrm{ns}}$ & 0.073 & 1.291 \\
\hline \multicolumn{8}{|c|}{ Family planning } \\
\hline No & & & & & 1 & & \\
\hline Yes & 0.555 & 0.238 & 1 & 0.02 & $1.742^{* *}$ & 1.093 & 2.776 \\
\hline
\end{tabular}

Note. Ns: Not significant; $\mathrm{Cl}$ : confidence interval; SE: standard error.

${ }^{*} P<0.10 ;{ }^{* *} P<0.05 ;{ }^{* * *} P<0.01$.

\section{Discussion}

The focal purpose of this research was to discuss the safemotherhood practices of tribes living in the CHT and to identify the associated causes. Engagement in standard safe motherhood practices and adoption of the ANC, SBA, and PNC services among the tribal women of Bangladesh were very poor $(12.7 \%)$, which is tremendously horrible. The results of the study showed that the use of the ANC services of the CHT tribal women from trained healthcare personnel during their pregnancy was almost half the national level, which is terrible. The results were significantly lower than data from the national survey, where the results represented $64 \%$ and $31 \%$ for women who received one ANC service and four ANC services, respectively (4). Regarding the delivery of safe maternity care in healthcare facilities, the survey of the CHT tribal women demonstrated that the percentage of mothers who gave birth to their babies in a medical hospital was $34 \%$ compared to the national survey data where $38 \%$ of surveyed women gave birth to their babies in a medical hospital (4). Based on the findings of the survey on the use of SBA services for CHT tribal women, the total 
Table 4. Binary Logistic Regression Analysis for Postnatal Healthcare Services

\begin{tabular}{|c|c|c|c|c|c|c|}
\hline \multirow{2}{*}{ Variables } & \multirow{2}{*}{ B } & \multirow{2}{*}{ SE } & \multirow{2}{*}{$P$ Value } & \multirow{2}{*}{ Odds Ratio } & \multicolumn{2}{|c|}{ 95\% CI For EXP (B) } \\
\hline & & & & & Lower & Upper \\
\hline \multicolumn{7}{|l|}{ Wealth index } \\
\hline Poor & & & & 1 & & \\
\hline Middle & 0.688 & 0.329 & 0.036 & $1.990^{* *}$ & 1.045 & 3.79 \\
\hline Rich & 1.336 & 0.376 & 0 & $3.804^{* * *}$ & 1.82 & 7.951 \\
\hline \multicolumn{7}{|c|}{ Distance to a health facility } \\
\hline$<5$ & & & & 1 & & \\
\hline $5-10$ & -0.318 & 0.329 & 0.332 & 0.727 & 0.382 & 1.385 \\
\hline $10+$ & -1.211 & 0.304 & 0 & $0.298^{* * *}$ & 0.164 & 0.54 \\
\hline \multicolumn{7}{|c|}{ Women's education } \\
\hline Illiterate & & & & 1 & & \\
\hline Primary & 0.254 & 0.413 & 0.539 & 1.289 & 0.573 & 2.898 \\
\hline Secondary & 0.402 & 0.419 & 0.337 & 1.495 & 0.658 & 3.399 \\
\hline Higher & 0.983 & 0.504 & 0.051 & $2.672^{* *}$ & 0.996 & 7.169 \\
\hline \multicolumn{7}{|c|}{ Husbands' education } \\
\hline Illiterate & & & & 1 & & \\
\hline Primary & -0.632 & 0.634 & 0.319 & 0.532 & 0.153 & 1.843 \\
\hline Secondary & 0.377 & 0.565 & 0.504 & 1.458 & 0.482 & 4.411 \\
\hline Higher & 1.244 & 0.609 & 0.041 & $3.471^{* *}$ & 1.052 & 11.452 \\
\hline \multicolumn{7}{|c|}{ Location of residence } \\
\hline Rural & & & & 1 & & \\
\hline Urban & 0.582 & 0.335 & 0.082 & $1.790^{*}$ & 0.929 & 3.449 \\
\hline \multicolumn{7}{|c|}{ Exposure of media (watching TV) } \\
\hline No & & & & 1 & & \\
\hline Yes & 0.602 & 0.287 & 0.036 & $1.826^{* *}$ & 1.041 & 3.203 \\
\hline \multicolumn{7}{|c|}{ Group of tribal } \\
\hline Chakma & & & & 1 & & \\
\hline Marma & -0.729 & 0.29 & 0.012 & 0.482 & 0.273 & 0.852 \\
\hline Tripura & 0.626 & 0.844 & 0.459 & $1.870^{* *}$ & 0.357 & 9.78 \\
\hline Other & -0.571 & 0.565 & 0.312 & 0.565 & 0.187 & 1.711 \\
\hline \multicolumn{7}{|c|}{ Family planning } \\
\hline No & & & & 1 & & \\
\hline Yes & 0.559 & 0.251 & 0.026 & $1.749^{* *}$ & 1.068 & 2.862 \\
\hline \multicolumn{7}{|l|}{ Religion } \\
\hline Buddhist & & & & 1 & & \\
\hline Other & -1.355 & 0.784 & 0.084 & $0.258^{*}$ & 0.055 & 1.2 \\
\hline
\end{tabular}

Note. Ns: Not significant; $\mathrm{Cl}$ : confidence interval; SE: standard error.

${ }^{*} P<0.10 ;{ }^{* *} P<0.05 ;{ }^{* * *} P<0.01$.

percentage of mothers with an SBA assisted delivery was $46 \%$ of which $34 \%$ and $12 \%$ of all deliveries took place in a hospital and at home, respectively. However, the findings from the national survey indicated that $52 \%$ of women had an SBA assisted delivery, of which $42 \%$ and $10 \%$ occurred in a hospital and at home, respectively (4). Based on the observation, the utilization of SBA services by the tribal women of CHT was below the national average (Figure 5).

For PNC utilization, data from this survey conducted on the CHT tribal women revealed that the overall pattern of the utilization of PNC by tribal girls was somewhat similar to the average across the country when compared with data of the national study at $36.4 \%$ and $39 \%$ for women who received PNC within 48 hours and 42 days of delivery (4). Globally, $68 \%$ of women received prenatal visit More than four times during pregnancy and about $80 \%$ of deliveries occurred in the presence of experienced birth attendants during 2012-2017 (7). Although postnatal check-ups have saved many lives, tribal women's postnatal check-ups in CHT, Bangladesh are significantly lower than national and global levels.

Regression results also demonstrated that women with higher educational positions have more excellent prospects of using ANC, SBA, and PNC services, along with giving birth to medical institutions. Additionally, higher education significantly increases literacy rates with increased awareness of the advantage of adopting safe motherhood care services. The technical knowledge of health shows how pregnant women need to care about maternal fitness/wellness. Thus, it is advisable to assume that it serves as a light to overcome ignorance in achieving maternity fitness care, which can be made through institutional education. Similar findings were reported in the study by Kamal (8), representing that women with 


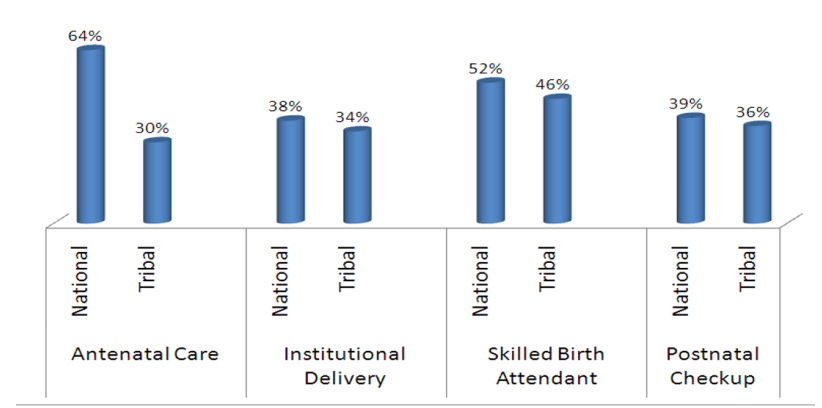

Figure 5. Utilization of MHCS in $\mathrm{CHT}$ Compared to the Mainstream People of Bangladesh. Note. MHCS: Maternal health care services; CHT: Chittagong Hill Tracts

higher educational status are more cognizant about the costs and benefits of utilizing MHCS.

The study also reported that the remoteness of health facilities was inversely linked to the MCHS utilization among the tribal women. Therefore, this study affirms that distance is a substantial impediment to the use of maternity care facilities among CHT tribal women despite their willingness to use these services. Furthermore, other obstacles such as the lack of good roads and suitable transportation severely impeded the utilization of MHCS by the tribal women in this study. It is clear that those who live far away, do not experience a lack of service. In addition, similar results were obtained in several other studies, confirming that the distance to the health institution significantly reduced accessibility to the services of maternal health care like the ANC, SBA, and institutional delivery (9-11).

Increased MHCS adoption among women with a higher wealth index was reported in this study as well. Based on the results of this survey, mothers with a higher wealth index were generally more educated and aware of active up-to-date health care facilities and thus recorded a higher percentage of utilizing full MHCS. The top wealthy women find no obstacle in taking the MHCS. The results of this study corroborate with those of previous studies, indicating that socioeconomic background determines MHCS receiving (12-16).

Furthermore, the findings demonstrated that women who were well-acquainted with family planning practices were more likely to engage in safe motherhood practices and adopt SBA, ANC, and PNC services. One keen observation is that women who utilize family planning services are more likely to receive information regarding safe motherhood practices from their family planning provider, which may lead to an increased willingness to use MHCS.

This shows that ANC services were low among women not practicing family planning (17) but higher among women who practiced family planning and adopted the services of SBAs during childbirth (10). On the other hand, no report is available regarding the positive relationship between the husband's contraceptive use and their wife's delivery at a health facility (18). It should be noted that SDG Target 3.7 is assuring universal access to family planning.

Women living in urban areas prefer PNC services and institutional delivery compared to their village tribes. Urban women also have robust access to information regarding available health services, including MHCS and, are even more educated and well placed in terms of socioeconomic status and wealth index. Moreover, most of the benefits associated with MHCS are higher in cities but less in rural areas.

Kamal also reported similar findings respecting urban residence delivering at a medical institution (19).

Regarding the husband's occupation, our results revealed that husbands with the best professions played a pioneering role in ensuring that their wives receive MHCS. Additionally, our findings showed that women having husbands with highly paid jobs were prone to utilize MHCS compared to those whose husbands had a less paid occupation like agriculture and labor. This is in line with the results obtained by Dhakal et al (20), which indicated that females with husbands in extremely paid jobs were more likely to obtain complete MHCS because their husbands were more informed and knowledgeable about the benefits of these services.

Similarly, women with good media exposure were prospective to use MHCS. The greater access to mass media can result in positive changes in behavioral patterns and preferences toward the utilization of MHCS. In addition, with regard to the age at first marriage, our findings represented that married women before the age of 18 years, particularly adolescent mothers, were less interested in giving birth to their children in health care centers compared to other competitors $(>18)$.

Further, studies have revealed that teenage/adolescent mothers seldom engage in safe motherhood practices because of having inadequate knowledge about the availability and benefits of these services.

\section{Conclusions}

In general, safe motherhood practices provide the mother and child a better chance of survival under the supervision of trained personnel at health care centres. The findings of the study demonstrated that the usage of maternity nursing is not standardized among the tribal women of CHT. Furthermore, the study highlighted socio-economic barriers as the dominant factor in disrupting access to maternity health care facilities for aboriginal women. Therefore, it is suggested that socio-economic barriers be breached through schooling, media campaigns, and the construction of health centres close to these tribal females, which would speed up secure motherhood procedures and the use of MHCS.

Moreover, several other parameters have a robust effect on improving the utilization of MHCS including establishing 'eco-friendly' industries such as the loom and 
garment industry and raising education levels for women and their husbands by creating educational institutions at the grass root level. Similarly, ensuring access to mass media, addressing the issue of distance to maternal health centers, discouraging early/teenage marriage, and making family planning programs more accessible are considered as the other influential factors in this regard. Additionally, the government should take the necessary steps to ensure that doctors are present in CHT hospitals by providing physicians with adequate facilities and incentives.

Most deliveries are still being handled by unSBAs. In addition to their training, there should be short-term training on MHCS at no cost with incentive packages for the tribes who have passed Secondary School Certificate (SSC) exams or dropped out of the school.

The findings of the survey further revealed that most indigenous people are employed as farmers, foresters, and part-time workers, and most of them are illiterate and not trained. As a result, these individuals cannot find a suitable career. Accordingly, income-incentive programs need to be created in the workplace in such a way that poultry and dairy farms can be financially independent in decisionmaking and MHCS adoption in order to strengthen the economic position of women.

The tribal groups of CHT are multilingual communities. They are different from each other in terms of language, rituals, religious, food and clothing styles, wedding ceremonies, housing patterns, and the like. In addition, they choose to live in a unique way for all these reasons. Thus, maternal health awareness can be improved by reinforcing their own cultural actions such as street drama, documentary movies, poem recitation, folk music, instructional rhythmic songs in dialect, and the like.

Finally, it should be mentioned that convictions and practices in maternal health facilities are the dominant variables that lead to the traditional acceptance of MHCS.

\section{Future Study}

A comparative study on the adoption of safe motherhood practices can be conducted between the CHT region and other rural communities in another part of the country to evaluate the environmental contributions to safe motherhood practices.

\section{Limitations}

Considering the retrospective nature of this study, it was impossible to verify whether respondents provided the right or wrong answer. The obtained data are acceptable, but there may have some errors due to the recall bias of the respondents. Due to the low level of participants' education in the region, some provided information may be incorrect. Apart from this, the tendency of having a shame in women in the hilly areas was also observable.

\section{Conflict of Interests}

Authors declare that they have no conflict of interests.

\section{Ethical Issues}

The study approval was obtained from the Board of Advanced Studies, Department of Computer Science and Engineering, International Islamic University Chittagong, Bangladesh (Reference no: 27/Education/IU-2013/828) dated on 19.02.2013).

\section{Financial Support}

The present study received no funding.

\section{Acknowledgments}

I am grateful to those who answered the research question. In addition, unique thanks go to assistants for their help in collecting the data. Finally, my sincere appreciation goes to my colleagues for their suggestions and advice throughout the study.

\section{References}

1. Karim ANMR, Kamal SMM, Islam MR. Antenatal Care Practices with Associated Factors among Tribal Women of Bangladesh. American Journal of Applied Mathematics and Statistics. 2018;6(4):149-157. doi:10.12691/ajams-6-4-5

2. UNICEF Data: Monitoring the situation of children and women. United Nations Children's Fund (UNICEF). United Nations Children's Fund (UNICEF) website. https:// data.unicef.org/topic/maternal-health/maternal-mortality. Published 2017.

3. World Health Organization (WHO). The World Health Report 2015: Trends in maternal mortality: 1990-2015. Geneva, Switzerland: WHO. http://www.who.int/ reproductivehealth/publications/monitoring/maternalmortality-2015/en/.

4. National Institute of Population Research and Training (NIPORT). 2014. Mitra and Associates, and ICF International. 2016. Bangladesh Demographic and Health Survey 2014. Dhaka, Bangladesh/Rockville Maryland: National Institute of Population Research and Training, Mitra and Associates, and ICF International; 2014.

5. Barkat A, Halim S, Poddar A, et al. Socio-economic baseline survey of Chittagong Hill Tracts. Human Development Research Centre (HDRC). http://www.hdrc-bd.com/wpcontent/uploads/2018/12/6.-Socio-economic-BaselineSurvey-of-Chittagong-Hill-Tracts.pdf. Published 2009.

6. Hossain DM. Socio-economic situation of the Indigenous people in the Chittagong Hill Tracts (CHT) of Bangladesh. Middle East Journal of Business. 2013;8(2):22-30. doi:10.5742/MEJN.2013.82231

7. World Health Organization (WHO). The World Health Report 2017. https://www.who.int/gho/maternal_health/ skilled_care/skilled_birth_attendance_text/en/.

8. Kamal SMM. Factors affecting utilization of skilled maternity care services among married adolescents in Bangladesh. Asian Popul Stud. 2009;5(2):153-170. doi:10.1080/17441730902992075

9. Mrisho M, Schellenberg JA, Mushi AK, et al. Factors affecting home delivery in rural Tanzania. Trop Med Int Health. 2007;12(7):862-872. doi:10.1111/j.13653156.2007.01855.x

10. Exavery A, Kante AM, Njozi M, et al. Predictors of mistimed, 
and unwanted pregnancies among women of childbearing age in Rufiji, Kilombero, and Ulanga districts of Tanzania. Reprod Health. 2014;11:63. doi:10.1186/1742-4755-11-63

11. Van Malderen C, Ogali I, Khasakhala A, et al. Decomposing Kenyan socio-economic inequalities in skilled birth attendance and measles immunization. Int J Equity Health. 2013;12:3. doi:10.1186/1475-9276-12-3

12. Anwar I, Sami M, Akhtar N, et al. Inequity in maternal health-care services: evidence from home-based skilledbirth-attendant programmes in Bangladesh. Bull World Health Organ. 2008;86(4):252-259. doi:10.2471/ blt.07.042754

13. Mazalale J, Kambala C, Brenner S, et al. Factors associated with delivery outside a health facility: cross-sectional study in rural Malawi. Trop Med Int Health. 2015;20(5):617-626. doi:10.1111/tmi.12473

14. Ono M, Matsuyama A, Karama M, Honda S. Association between social support and place of delivery: a crosssectional study in Kericho, Western Kenya. BMC Pregnancy Childbirth. 2013;13:214. doi:10.1186/1471-2393-13-214

15. Mahara G, Asweto C, Cao K, et al. Utilization of ANC and PNC Services in Nepal: A Multivariate Analysis
Based on Nepal Demographic Health Survey 2001 and 2006. Am J Health Res. 2015;3(6):318-327. doi:10.11648/j. ajhr.20150306.11

16. Babalola S, Fatusi A. Determinants of use of maternal health services in Nigeria - looking beyond individual and household factors. BMC Pregnancy Childbirth. 2009;9(1):43. doi:10.1186/1471-2393-9-43

17. Edward B. Factors influencing the utilisation of antenatal care content in Uganda. Australas Med J. 2011;4(9):516526. doi:10.4066/amj.2011.849

18. Nathenson S. Indigenous health disparities. In: Michalos AC, ed. Encyclopedia of Quality of Life and WellBeing Research. Dordrecht: Springer; 2014:137-311. doi:10.1007/978-94-007-0753-5

19. Kamal SM, Hassan CH, Alam GM. Determinants of institutional delivery among women in Bangladesh. Asia Pac J Public Health. 2015;27(2):NP1372-1388. doi:10.1177/1010539513486178

20. Dhakal S, Chapman GN, Simkhada PP, van Teijlingen ER, Stephens J, Raja AE. Utilisation of postnatal care among rural women in Nepal. BMC Pregnancy Childbirth. 2007;7(1):19. doi:10.1186/1471-2393-7-19

(C) 2020 The Author (s); This is an open-access article distributed under the terms of the Creative Commons Attribution License (http://creativecommons.org/licenses/by/4.0), which permits unrestricted use, distribution, and reproduction in any medium, provided the original work is properly cited. 